\title{
Public crack cocaine smoking and willingness to use a supervised inhalation facility: implications for street disorder
}

\author{
Kora DeBeck ${ }^{1}$, Jane Buxton ${ }^{2}$, Thomas Kerr ${ }^{1,3}$, Jiezhi Qi ${ }^{1}$, Julio Montaner ${ }^{1,3}$, Evan Wood ${ }^{1,3^{*}}$
}

\begin{abstract}
Background: The health risks of crack cocaine smoking in public settings have not been well described. We sought to identify factors associated with public crack smoking, and assess the potential for a supervised inhalation facility to reduce engagement in this behavior, in a setting planning to evaluate a medically supervised crack cocaine smoking facility.

Methods: Data for this study were derived from a Canadian prospective cohort of injection drug users. Using multivariate logistic regression we identified factors associated with smoking crack cocaine in public areas. Among public crack smokers we then identified factors associated with willingness to use a supervised inhalation facility.

Results: Among our sample of 623 people who reported crack smoking, 61\% reported recently using in public locations. In multivariate analysis, factors independently associated with public crack smoking included: daily crack cocaine smoking; daily heroin injection; having encounters with police; and engaging in drug dealing. In sub analysis, $71 \%$ of public crack smokers reported willingness to use a supervised inhalation facility. Factors independently associated with willingness include: female gender, engaging in risky pipe sharing; and having encounters with police.

Conclusion: We found a high prevalence of public crack smoking locally, and this behavior was independently associated with encounters with police. However, a majority of public crack smokers reported being willing to use a supervised inhalation facility, and individuals who had recent encounters with police were more likely to report willingness. These findings suggest that supervised inhalation facilities offer potential to reduce street-disorder and reduce encounters with police.
\end{abstract}

\section{Background}

The use of illicit drugs in public settings, including street, alleys and parks is both a public health and public order concern in many urban areas [1-3]. To date, the use of injection drugs in public settings has received the most attention from policy-makers and public health researchers $[2,4,5]$. Public injecting is known to present problems for citizens who reside in or around areas where public drug use is prevalent, and scientific studies have documented that using injection drugs in public settings can discourage safer injecting practices resulting in many public health problems, including increased risk

\footnotetext{
* Correspondence: uhri-ew@cfenet.ubc.ca

'British Columbia Centre for Excellence in HIV/AIDS, Vancouver, Canada Full list of author information is available at the end of the article
}

for drug overdose events and HIV and other bloodborne infections [6-8]. As a result, some cities have implemented supervised injection facilities which aim to provide an alternative injecting environment that reduces both the health risks associated with injection drug use and the street disorder it can generate [9-13]. While supervised injection facilities have been noted to have measurable success in achieving these public health and public order objectives, the use of inhalable drugs, particularly crack cocaine smoking, has been growing in popularity in many street-based drug scenes [14-16].

In Vancouver, Canada the popularity of crack cocaine and ease of administration through smoking has made public crack cocaine use a common feature of the streets in the city's drug use epicentre, known as the Downtown Eastside [17]. Public crack cocaine smoking 
is posing a growing burden for law enforcement agencies responsible for maintaining public order [18]. In addition, the health and social harms associated with crack cocaine smoking are extensive. Compared to other drug user populations, crack users are more likely to engage in risky behaviors [19-21] and illegal activities $[22,23]$ and to experience homelessness [14] and health problems [14,24-27], yet are less likely to access health and social services [28]. It has also been recently documented that daily crack cocaine smokers are at a fourfold greater risk of contracting HIV compared to their drug using peers who smoke crack cocaine less often or not at all [16].

Given the dramatic rise in crack cocaine smoking and the public order and public health concerns associated with it, the need for targeted interventions for people who smoke crack cocaine is unambiguous. One potential intervention that is receiving increasing attention from public health officials, health researchers and local community groups is supervised drug consumption facilities analogous to supervised injection sites but that accommodate crack smoking and distribute drug consumption materials specific to safer inhalation (such as sterile crack pipes, mouthpieces, and screens) [16,29-33]. The Canadian Institutes of Health Research recently approved funding to conduct a randomized control trial to evaluate the impact of a supervised inhalation facility on access to medical and social services, particularly addiction treatment, among Vancouver-based crack cocaine smokers [34].

Previous studies have assessed general willingness among local drug users to use a supervised inhalation facility [35,36]; however, these studies were not primarily concerned with street disorder and therefore did not consider the specific risks associated with smoking crack cocaine in public areas nor did they assess willingness to use an inhalation facility among public crack cocaine smokers exclusively. Therefore we conducted a study focused on public crack smokers to identify factors associated with this practice. We also sought to assess willingness to use an inhalation facility among individuals who smoke crack cocaine in public areas to determine the potential impact a supervised inhalation facility might have on street disorder in Vancouver, Canada.

\section{Methods}

Data for this study was obtained from the Vancouver Injection Drug Users Study, which is an open prospective cohort that began enrolling people who inject drugs (IDU) through street outreach as self-referral in May 1996. This study has been described in detail previously $[37,38]$. In brief, to be eligible participants at recruitment must reside in the Greater Vancouver Regional District, have injected illicit drugs in the previous month, and provide written informed consent. At enrollment and on bi-annual basis participants complete an interviewer-administered questionnaire, and after an examination with a study nurse provide a blood sample for serologic testing. At each study visit participants are provided with a stipend ( $\$ 20 \mathrm{CDN})$ for their time. The study has received ethics approval from St. Paul's Hospital and the University of British Columbia's Research Ethics Board. The present analyses are restricted to those participants who reported smoking crack cocaine in the last six months, and were seen for study followup during the period of November 2008 and June 2009 as measures for one of our outcomes of interest are available only for this sample period.

In our first analysis among crack cocaine smokers, the outcome of interest was using drugs (non-injection) in public areas in the last six months. As in previous analyses, public areas included city streets, parks, public washrooms, parking lots, clubs or bars and abandoned buildings. To characterize our outcome of interest we a priori selected a range of socio-demographic and behavioural variables we hypothesized might be relevant to smoking crack cocaine in public areas. This selection was informed by the 'risk environment framework' and previous analyses among street-involved drug users highlighting connections between social, structural and environmental level factors and risky drug consumption practices [14,31,39-41]. Variables included: age (per year older); gender (female vs. male); Aboriginal Ancestry (yes vs. no); limited access to private space, defined as answering "no" to the question: "Do you have a private indoor space for socializing with friends and acquaintances?" or reporting that the number of guests they were allowed to have in their residence at one time was restricted to less than three (yes vs. no); daily cocaine injection (yes vs. no); daily heroin injection (yes vs. no); daily crack cocaine smoking (yes vs. no); non-fatal overdose, self identified by participants (yes vs. no); encounters with police in the last month, defined as being questioned, searched or stopped by police (yes vs. no); being a victim of violence defined as being physically assaulted (yes vs. no); sex trade involvement, defined as exchanging sex for money, shelter, drugs or other commodities (yes vs. no), and participation in drug dealing (yes vs. no). Unless otherwise stated, all drug use and behavioural variables refer to the previous six month period.

In a second analysis, we sought to assess and identify predictors of willingness to use a supervised inhalation room. Because we were particularly concerned with public drug use we restricted our sample to crack cocaine smokers that reported recently using noninjection drugs in public areas. To measure willingness we asked participants "If there was a safe place to 
smoke your drugs (ventilated inhalation room), close to where you buy or use, would you use it?"

Variables of interest for our second analysis were also selected a priori based on factors we hypothesized might be associated with willingness to use an inhalation room. These included age (per year older); gender (female vs. male); Aboriginal Ancestry (yes vs. no); limited access to private space, as defined above (yes vs. no); drug scene exposure, defined as spending an average of seven or more hours on the street each day in Vancouver's drug use epicentre in the previous six months (yes vs. no); most drug use in public areas, defined based on reports that public locations were where they most frequently used drugs (yes vs. no); daily crack cocaine smoking (yes vs. no); risky pipe sharing, defined as reporting sharing a crack pipe or mouthpiece in the same six month period as having burns or sores on their mouth (yes vs. no); encounters with police in the last month (yes vs. no); and being a victim of violence (yes vs. no). As above, unless otherwise stated, all drug use and behavioural variables refer to the previous six month period.

For both of our first and second analyses, we used univariate and multivariate statistics to determine factors associated with our outcomes of interest. In univariate analysis categorical explanatory variables were analyzed using Pearson's chi-square test and continuous variables were analyzed using the Wilcoxon rank sum test. Fisher's exact test was used when one or more of the cell counts was less than or equal to five. To evaluate factors independently associated with our outcomes of interest, all variables that were $p<0.05$ in univariate analyses were entered into the respective multivariate regression models. All statistical analyses were performed using SAS software version 9.1 (SAS, Cary, NC). All p-values are two sided.

\section{Results}

During the study period 623 participants were seen for study follow-up visits and reported smoking crack cocaine in the last six months. These included 249 (40\%) women and 231 (37\%) persons who identified as Aboriginal. The median number of times that participants reported smoking crack cocaine in an average day was 4 (interquartile range $=2-10$ ). Among our sample of 623 crack smokers, a total of $382(61 \%)$ reported using in public areas in the last six months. The characteristics of the study sample stratified by public drug use are presented in Table 1, and the univariate analyses of behavioral and socio-demographic variables associated with public drug use among crack cocaine smokers are presented in Table 2. The results of the multivariate logistic regression for factors associated with public drug use among crack cocaine smokers are also shown
Table 1 Characteristics of crack cocaine smokers stratified by public drug use $(n=623)$

\begin{tabular}{|c|c|c|}
\hline \multirow[b]{2}{*}{ Characteristic } & \multicolumn{2}{|c|}{ Public drug use $^{a}$} \\
\hline & $\begin{array}{c}\text { Yes } n=382 \\
n(\%)\end{array}$ & $\begin{array}{c}\text { No } n=241, \\
n(\%)\end{array}$ \\
\hline \multicolumn{3}{|l|}{ Age pre year older } \\
\hline (Median, IQR) $^{\mathbf{c}}$ & $43(37-49)$ & $46(40-50)$ \\
\hline \multicolumn{3}{|l|}{ Female Gender } \\
\hline Yes & $145(38)$ & $104(43)$ \\
\hline No & $237(62)$ & $137(57)$ \\
\hline \multicolumn{3}{|l|}{ Aboriginal Ancestry } \\
\hline Yes & $137(36)$ & $94(39)$ \\
\hline No & $245(64)$ & $147(61)$ \\
\hline \multicolumn{3}{|c|}{$\begin{array}{l}\text { Limited Access to Private } \\
\text { Space }^{d}\end{array}$} \\
\hline Yes & $316(83)$ & $169(70)$ \\
\hline No & $66(17)$ & $72(30)$ \\
\hline \multicolumn{3}{|c|}{ Daily Cocaine Injection ${ }^{d}$} \\
\hline Yes & $39(10)$ & $9(4)$ \\
\hline No & $343(90)$ & $232(96)$ \\
\hline \multicolumn{3}{|c|}{ Daily Heroin Injection ${ }^{d}$} \\
\hline Yes & $107(28)$ & $25(10)$ \\
\hline No & $275(72)$ & $216(90)$ \\
\hline \multicolumn{3}{|c|}{ Daily Crack Smoking ${ }^{d}$} \\
\hline Yes & $220(58)$ & $72(30)$ \\
\hline No & $162(42)$ & $169(70)$ \\
\hline \multicolumn{3}{|c|}{ Overdose (non-fatal) ${ }^{d}$} \\
\hline Yes & $18(5)$ & $3(1)$ \\
\hline No & $364(95)$ & $238(99)$ \\
\hline \multicolumn{3}{|c|}{ Encounters with police ${ }^{e}$} \\
\hline Yes & $114(30)$ & $35(15)$ \\
\hline No & $268(70)$ & $206(85)$ \\
\hline \multicolumn{3}{|l|}{ Victim of Violence ${ }^{d}$} \\
\hline Yes & $77(20)$ & $30(12)$ \\
\hline No & $305(80)$ & $211(88)$ \\
\hline \multicolumn{3}{|l|}{ Sex Trade ${ }^{d}$} \\
\hline Yes & $60(16)$ & $19(8)$ \\
\hline No & $322(84)$ & $222(92)$ \\
\hline \multicolumn{3}{|l|}{ Drug Dealing ${ }^{d}$} \\
\hline Yes & $150(39)$ & $46(19)$ \\
\hline No & $232(61)$ & $195(81)$ \\
\hline
\end{tabular}

Note: ${ }^{a}$ Public locations include: city streets, parks, public washrooms, parking lots, clubs or bars, and abandon buildings; ${ }^{c} \mathrm{IQR}=$ Inter Quartile Range; ${ }^{\mathrm{d}}$ Denotes activities or situations referring to previous 6 months; ${ }^{\text {e }}$ Denotes activities or situations referring to previous month.

in Table 2. Factors that remained independently associated with our outcome of interest included: daily heroin injection, daily crack cocaine smoking, encounters with police and drug dealing (see Table 2).

For our second analysis, the demographic and behavioural characteristics of public crack cocaine smokers stratified by willingness to use a supervised inhalation room are presented in Table 3, and the univariate results of factors associated with willingness to use a 
Table 2 Univariate and multivariate analyses of factors associated with public drug use among crack cocaine smokers ${ }^{a}$ $(n=623)$

\begin{tabular}{|c|c|c|c|c|}
\hline \multirow[b]{2}{*}{ Characteristic } & \multicolumn{2}{|c|}{ Univariate } & \multicolumn{2}{|c|}{ Multivariate } \\
\hline & $\mathrm{OR}^{\mathrm{b}}(95 \% \mathrm{Cl})$ & $p$-value ${ }^{c}$ & AOR $(95 \% \mathrm{Cl})$ & $p$-value \\
\hline \multicolumn{5}{|l|}{ Older Age } \\
\hline Per year older & $0.96(0.94-0.98)$ & $<0.001$ & $0.98(0.96-1.00)$ & 0.065 \\
\hline \multicolumn{5}{|l|}{ Gender } \\
\hline Female vs. Male & $0.81(0.58-1.12)$ & 0.197 & & \\
\hline \multicolumn{5}{|l|}{ Aboriginal Ancestry } \\
\hline Yes vs. No & $0.87(0.63-1.22)$ & 0.429 & & \\
\hline \multicolumn{5}{|c|}{ Limited Access to Private Space ${ }^{d}$} \\
\hline Yes vs. No & $2.04(1.39-2.99)$ & $<0.001$ & $1.49(0.99-2.26)$ & 0.058 \\
\hline \multicolumn{5}{|c|}{ Daily Cocaine Injection ${ }^{d}$} \\
\hline Yes vs. No & $2.93(1.39-6.17)$ & 0.003 & $1.70(0.77-3.75)$ & 0.190 \\
\hline \multicolumn{5}{|c|}{ Daily Heroin Injection ${ }^{d}$} \\
\hline Yes vs. No & $3.36(2.10-5.38)$ & $<0.001$ & $1.95(1.17-3.27)$ & 0.011 \\
\hline \multicolumn{5}{|c|}{ Daily Crack Cocaine Smoking ${ }^{d}$} \\
\hline Yes vs. No & $3.19(2.26-4.49)$ & $<0.001$ & $2.17(1.49-3.14)$ & $<.001$ \\
\hline \multicolumn{5}{|c|}{ Overdose (non-fatal)*d } \\
\hline Yes vs. No & $3.92(1.13-20.98)$ & 0.020 & $2.04(0.55-7.61)$ & 0.288 \\
\hline \multicolumn{5}{|c|}{ Encounters with Police ${ }^{e}$} \\
\hline Yes vs. No & $2.50(1.64-3.81)$ & $<0.001$ & $1.69(1.07-2.68)$ & 0.025 \\
\hline \multicolumn{5}{|l|}{ Victim of Violence $^{d}$} \\
\hline Yes vs. No & $1.78(1.12-2.80)$ & 0.013 & $1.52(0.92-2.51)$ & 0.100 \\
\hline \multicolumn{5}{|l|}{ Sex Trade ${ }^{d}$} \\
\hline Yes vs. No & $2.18(1.26-3.75)$ & 0.004 & $1.30(0.72-2.38)$ & 0.386 \\
\hline \multicolumn{5}{|l|}{ Drug Dealing ${ }^{d}$} \\
\hline Yes vs. No & $2.74(1.87-4.01)$ & $<0.001$ & $1.61(1.06-2.47)$ & 0.027 \\
\hline
\end{tabular}

Note: ${ }^{a}$ Public areas included: city streets, parks, public washrooms, parking lots, clubs or bars, and abandon buildings; ${ }^{\mathrm{b}} \mathrm{OR}=\mathrm{Odds}$ Ratio, $\mathrm{Cl}=\mathrm{Confidence}$ Interval; AOR = Adjusted Odds Ratio; 'Unless otherwise stated, values are based on Pearson's chi-square test for categorical variables and Wilcoxon rank sum test for continuous variables with 1 degree of freedom; ${ }^{d}$ Denotes activities or situations referring to previous 6 months; ${ }^{e}$ Denotes activities or situations referring to previous month. *p-value and $95 \% \mathrm{Cl}$ reported from Fisher's Exact Test as $25 \%$ of cells had expected counts less than 5.

supervised inhalation room are presented in Table 4. The results of the multivariate logistic regression for factors associated with willingness to use a supervised inhalation room are also shown in Table 4. Factors that remained independently associated with willingness included: female gender, risky pipe sharing and recent encounters with police (see Table 4.).

\section{Discussion}

We found that the majority of crack cocaine smokers in our study reported having used drugs in public areas at some point in the last six months. This group was more likely to be higher-intensity drug users with respect to heroin injection and crack cocaine smoking, have encounters with the police and be involved in drug dealing. Of these public crack cocaine smokers, $71 \%$ reported being willing to use a supervised inhalation room if one was available. Individuals who reported being willing were more likely to be female, engage in risky pipe sharing and have encounters with the police.
The profile of public crack cocaine smokers as higherintensity drug users who have interactions with the criminal justice system is reflective of previous findings describing public injection drug user populations $[1,5]$. The association between drug dealing and public crack use may reflect the increased amount of time individuals spend on the street when engaged in street-level drug dealing. It may also be a function of the accessibility of drugs and additional resources gained through drug dealing which may lead to greater drug consumption and hence a greater likelihood for consuming in public areas [23].

Our finding that $71 \%$ of public crack cocaine smokers are willing to use an inhalation facility also supports previous willingness estimates conducted among the general population of Vancouver-based illicit drug users and suggests that an intervention of this nature will likely reach the target population [36]. The high degree of willingness that this study found among public crack cocaine smokers to use an inhalation facility suggests that, like supervised injection facilities, these interventions are likely to 
Table 3 Characteristics of crack cocaine smokers who use drugs in public stratified by willingness to use a supervised inhalation room $(n=382)$

\begin{tabular}{|c|c|c|}
\hline \multirow[b]{2}{*}{ Characteristic } & \multicolumn{2}{|c|}{ Willing to use SIR $^{a}$} \\
\hline & $\begin{array}{c}\text { Yes } n=271 \\
n(\%)\end{array}$ & $\begin{array}{c}\text { No } n=111, \\
n(\%)\end{array}$ \\
\hline \multicolumn{3}{|l|}{ Age pre year older } \\
\hline$(\text { Median, } \mathrm{IQR})^{\mathrm{C}}$ & $43(37-49)$ & $44(37-48)$ \\
\hline \multicolumn{3}{|l|}{ Female Gender } \\
\hline Yes & $117(43)$ & $28(25)$ \\
\hline No & $154(57)$ & $83(75)$ \\
\hline \multicolumn{3}{|l|}{ Aboriginal Ancestry } \\
\hline Yes & $108(40)$ & $29(26)$ \\
\hline No & $163(60)$ & $82(74)$ \\
\hline \multicolumn{3}{|c|}{$\begin{array}{l}\text { Limited Access to Private } \\
\text { Space e }\end{array}$} \\
\hline Yes & $230(85)$ & $86(77)$ \\
\hline No & $41(15)$ & $25(23)$ \\
\hline \multicolumn{3}{|c|}{ Drug Scene Exposure ${ }^{e, f}$} \\
\hline Yes & $157(58)$ & $49(44)$ \\
\hline No & $114(42)$ & $62(56)$ \\
\hline \multicolumn{3}{|c|}{$\underset{e}{\text { Most Drug Use in Public Areas }}$} \\
\hline Yes & $140(52)$ & $43(39)$ \\
\hline No & $131(48)$ & $68(61)$ \\
\hline \multicolumn{3}{|c|}{ Daily Crack Cocaine Smoking ${ }^{\text {e }}$} \\
\hline Yes & $164(61)$ & $56(50)$ \\
\hline No & 107 (39) & $55(50)$ \\
\hline \multicolumn{3}{|l|}{ Risky Pipe Sharing e } \\
\hline Yes & $38(14)$ & $3(3)$ \\
\hline No & $233(86)$ & $108(97)$ \\
\hline \multicolumn{3}{|c|}{ Encounters with Police ${ }^{d}$} \\
\hline Yes & $92(34)$ & $22(20)$ \\
\hline No & $179(66)$ & $89(80)$ \\
\hline \multicolumn{3}{|l|}{ Victim of Violence ${ }^{e}$} \\
\hline Yes & $53(20)$ & $24(22)$ \\
\hline No & $218(80)$ & $87(78)$ \\
\hline
\end{tabular}

Note: ${ }^{c} \mathrm{IQR}=$ Inter Quartile Range; ${ }^{\mathrm{d}}$ Denotes activities or situations referring to previous 6 months; ${ }^{e}$ Denotes activities or situations referring to previous month; ${ }^{f}$ Drug scene exposure was defined as spending an average of 7 or more hours on the street each day in Vancouver's drug use epicenter in the previous six months.

successfully encourage public drug users to relocate to indoor venues.

The increased likelihood of being willing to use an inhalation facility among female participants may reflect heightened vulnerability of women involved in street drug use and it is noteworthy that Vancouver's supervised injection facility has had success in attracting vulnerable female drug users and providing them with safer alternatives to street-based drug using venues. In previous research female IDU have described the unique role that Vancouver's supervised injection facility has played in promoting their physical security and health safety [42].

Interestingly, one of the common features among both public crack cocaine smokers and those who are willing to use a supervised inhalation facility is their elevated likelihood of recently having encounters with law enforcement. This suggests that public crack cocaine smokers who are the subject of law enforcement attention are very willing to relocate to alternative off-street and health-focussed environments if they were made available. Indeed, our data indicate that $81 \%$ of public crack cocaine smokers who have had a recent encounter with police are willing to use a supervised inhalation facility.

A key implication of these findings is that there is a large demand for supervised inhalation rooms among individuals that are potentially key contributors to drugrelated street disorder. The association between public crack smoking and encounters with police suggests that interventions of this nature are likely to target a critical sub-population of drug users and could be a valuable tool for police in the management of street disorder. Previous studies have found that Vancouver police regularly refer public injection drug users to the local supervised injection facility [43]. Since our analysis indicates that local police are already frequently interacting with public crack smokers the establishment of a supervised inhalation facility could provide a unique opportunity for police to direct this vulnerable group to a lowthreshold service where they will have opportunities to be linked with appropriate health and social services.

It is critical to note that although this study suggests that supervised inhalation facilities could aid in the reduction of public disorder, drug consumption facilities do not address the route causes of street disorder and are not appropriate substitutes for other essential health and social interventions such as supportive housing and addiction treatment. To be effective supervised inhalation facilities should be integrated into broader comprehensive approaches to addressing the problems associated with illicit drug addiction.

This study has a number of limitations. Firstly, VIDUS is a community recruited non-randomized sample and therefore our findings may not be generalizable to other settings. If supervised inhalation facilities are being considered in other settings, willingness studies should be conducted among the local target population and should not rely on the findings emerging from our setting. The generalizability of our findings is also limited by our study sample which was restricted to individuals with a history of injection drug use. Crack cocaine smokers who did not have a history of injection drug use were not eligible for our study. Given the harms associated with injection drug use we anticipate that if a selection 
Table 4 Univariate and multivariate analyses of factors associated with willingness to use a supervised inhalation room among participants that smoke crack cocaine and use drugs in public locations $(\mathbf{n}=\mathbf{3 8 2}$ )

\begin{tabular}{|c|c|c|c|c|}
\hline \multirow[b]{2}{*}{ Characteristic } & \multicolumn{2}{|l|}{ Univariate } & \multicolumn{2}{|c|}{ Multivariate } \\
\hline & $\mathrm{OR}^{\mathrm{a}}(95 \% \mathrm{Cl})$ & $p$-value & $\operatorname{AOR}^{c}(95 \% \mathrm{Cl})$ & $p$-value \\
\hline \multicolumn{5}{|l|}{ Older Age } \\
\hline Per year older & $1.01(0.98-1.04)$ & 0.446 & & \\
\hline \multicolumn{5}{|l|}{ Gender } \\
\hline Female vs. Male & $2.25(1.38-3.68)$ & 0.001 & $2.11(1.26-3.55)$ & 0.005 \\
\hline \multicolumn{5}{|l|}{ Aboriginal Ancestry } \\
\hline Yes vs. No & $1.87(1.15-3.05)$ & 0.011 & $1.61(0.96-2.72)$ & 0.072 \\
\hline \multicolumn{5}{|c|}{ Limited Access to Private Space ${ }^{d}$} \\
\hline Yes vs. No & $1.63(0.94-2.84)$ & 0.083 & & \\
\hline \multicolumn{5}{|c|}{ Drug Scene Exposure ${ }^{d}$} \\
\hline Yes vs. No & $1.74(1.12-2.72)$ & 0.014 & $1.40(0.86-2.28)$ & 0.181 \\
\hline \multicolumn{5}{|c|}{ Most Drug Use in Public Areas ${ }^{d}$} \\
\hline Yes vs. No & $1.69(1.08-2.65)$ & 0.022 & $1.39(0.85-2.28)$ & 0.187 \\
\hline \multicolumn{5}{|c|}{ Daily Crack Cocaine Smoking ${ }^{d}$} \\
\hline Yes vs. No & $1.51(0.96-2.35)$ & 0.071 & & \\
\hline \multicolumn{5}{|l|}{ Binge Drug Use ${ }^{d}$} \\
\hline \multicolumn{5}{|l|}{ Yes } \\
\hline \multicolumn{5}{|l|}{ Risky Pipe Sharing* d } \\
\hline Yes vs. No & $5.87(1.79-30.29)$ & $<0.001$ & $5.50(1.63-18.56)$ & 0.006 \\
\hline \multicolumn{5}{|c|}{ Encounters with Police ${ }^{e}$} \\
\hline Yes vs. No & $2.08(1.22-3.53)$ & 0.006 & $2.09(1.20-3.65)$ & 0.010 \\
\hline \multicolumn{5}{|l|}{ Victim of Violence $^{d}$} \\
\hline Yes vs. No & $0.88(0.51-1.52)$ & 0.648 & & \\
\hline
\end{tabular}

Note: ${ }^{\mathrm{a}} \mathrm{OR}=$ Odds Ratio, $\mathrm{Cl}=$ Confidence Interval; ${ }^{\mathrm{b}}$ Unless otherwise stated, values are based on Pearson's chi-square test for categorical variables and Wilcoxon rank sum test for continuous variables with 1 degree of freedom; ${ }^{\mathrm{C}} \mathrm{AOR}=$ Adjusted Odds Ratio; ${ }^{\mathrm{d}}$ Denotes activities or situations referring to previous 6 months; ${ }^{\mathrm{e}}$ Denotes activities or situations referring to previous month. ${ }^{*} \mathrm{p}$-value and $95 \% \mathrm{Cl}$ reported from Fisher's Exact Test as $25 \%$ of cells had expected counts less than 5.

effect were present it would likely bias our sample towards high risk drug users, suggesting that this group would be an appropriate target population for public health intervention. We should also note that among our study sample daily crack cocaine smoking was significantly more common than daily injecting, suggesting that despite the requirement of a history of injecting, our sample represents a primarily crack cocaine smoking population. Secondly, some of our measures relied on self-report and could be vulnerable to socially desirable reporting. This would have likely been of most relevant to our measure of willingness, since respondents might perceive a pressure to report being willing to engage with low-threshold services of this nature given the widespread activism among local drug users in our study setting to implement supervised drug consumption facilities [32]. While it is possible that some respondents may over-report willingness, a previous study comparing measures of willingness to use a supervised injection facility before it was established with later reports of actual attendance after an injection facility was established suggests that willingness measures are good predictors of later behaviour among this population [44]. Lastly, socially desirable reporting could have influenced reports of stigmatized behaviour, such as public drug use leading to an underestimation of public crack smoking. If social desirability was an issue in our study we suspect our finding would be a conservative indication of the prevalence of and harms associated with public drug use among crack cocaine smokers.

In summary, our study found that locally public crack smoking is a common practice that is also associated with recent encounters with police. We found that the majority of public crack smokers were willing to use an inhalation facility if one were available. Furthermore, public crack smokers who had recent encounters with police were even more likely to be willing to use an inhalation room, suggesting that supervised inhalation facilities may offer unique opportunities to decrease one component of drug-related street disorder and reduce the burden on local law enforcement agencies.

\section{Funding}

The study was supported by the US National Institutes of Health (R01DA011591) and (R01DA021525) and the 
Canadian Institutes of Health Research (MOP-79297, RAA-79918). Thomas Kerr is supported by the Michael Smith Foundation for Health Research and the Canadian Institutes of Health Research. Kora DeBeck is supported by a Michael Smith Foundation for Health Research Senior Graduate Trainee Award and a Canadian Institutes of Health Research Doctoral Research Award. Julio Montaner has received an Avant-Garde award (DP1DA026182) from the National Institute of Drug Abuse, US National Institutes of Health.

\section{Acknowledgements}

The authors thank the study participants for their contribution to the research, as well as current and past researchers and staff. We would specifically like to thank Deborah Graham, Tricia Collingham, Carmen Rock, Peter Vann, Caitlin Johnston, Steve Kain, and Calvin Lai for their research and administrative assistance.

\section{Author details}

${ }^{1}$ British Columbia Centre for Excellence in HIV/AIDS, Vancouver, Canada. ${ }^{2}$ School of Population and Public Health, University of British Columbia, Vancouver, Canada. ${ }^{3}$ Division of AIDS, Department of Medicine, University of British Columbia, Vancouver, Canada.

\section{Authors' contributions}

The specific contributions of each author are as follows: KD, TK, and EW were responsible for study design; JQ conducted the statistical analyses; KD prepared the first draft of the analysis; TK, JB, JM and EW contributed to the main content and provided critical comments on the final draft. All authors approved the final manuscript.

\section{Competing interests}

JM has received grants from, served as an ad hoc advisor to, or spoke at various events sponsored by; Abbott, Argos Therapeutics, Bioject Inc, Boehringer Ingelheim, BMS, Gilead Sciences, GlaxoSmithKline, Hoffmann-La Roche, Janssen-Ortho, Merck Frosst, Pfizer, Schering, Serono Inc, TheraTechnologies, Tibotec, Trimeris.

Authors declare no other competing interests.

Received: 4 November 2010 Accepted: 23 February 2011 Published: 23 February 2011

\section{References}

1. Navarro C, Leonard L: Prevalence and factors related to public injecting in Ottawa, Canada: implications for the development of a trial safer injecting facility. International Journal of Drug Policy 2004, 15(4):275-284.

2. Cusick L, Kimber J: Public perceptions of public drug use in four UK urban sites. International Journal of Drug Policy 2007, 18(1):10-17.

3. Weisburd D, Mazerolle LG: Crime and Disorder in Drug Hot Spots: Implications for Theory and Practice in Policing. Police Quarterly 2000, 3(3):331.

4. DeBeck K, Small W, Wood E, Li K, Montaner J, Kerr T: Public injecting among a cohort of injecting drug users in Vancouver, Canada. J Epidemiol Community Health 2009, 63(1):81-86.

5. Green T, Hankins C, Palmer D, Boivin J, Platt R: Ascertaining the need for a supervised injecting facility (SIF): the burden of public injecting in Montreal, Canada. J Drug Iss 2003, 33(3):713.

6. Small W, Rhodes T, Wood E, Kerr T: Public injection settings in Vancouver: physical environment, social context and risk. International Journal of Drug Policy 2007, 18(1):27-36.

7. Cooper H, Moore L, Gruskin S, Krieger N: The impact of a police drug crackdown on drug injectors' ability to practice harm reduction: A qualitative study. Soc Sci Med 2005, 61(3):673-684.

8. Maher L, Dixon D: Policing and public health: Law enforcement and harm minimization in a street-level drug market. Brit J Criminol 1999, 39(4):488-512.
9. Kimber J, Dolan K, Van Beek I, Hendrich D, Zurhold H: Drug consumption facilities: an update since 2000. Drug Alcohol Rev 2003, 22(2):227-233.

10. MSIC Evaluation Committee: Final report of the evaluation of the Sydney medically supervised injecting centre. 2003.

11. Wood E, Kerr T, Montaner JS, Strathdee SA, Wodak A, Hankins CA, Schechter MT, Tyndall MW: Rationale for evaluating North America's first medically supervised safer-injecting facility. Lancet Infect Dis 2004, 4(5):301-6.

12. Dolan K, Kimber J, Fry C, McDonald D, Fitzgerald J, Trautmann F: Drug consumption facilities in Europe and the establishment of supervised injecting centres in Australia. Drug Alcohol Rev 2000, 19(3):337-346.

13. Wright NM, Tompkins CN: Supervised injecting centres. BMJ 2004, 328(7431):100-102

14. Fischer B, Rehm J, Patra J, Kalousek K, Haydon E, Tyndall M, El-Guebaly N: Crack across Canada: comparing crack users and crack non-users in a Canadian multi-city cohort of illicit opioid users. Addiction 2006, 101(12):1760-1770

15. Werb D, DeBeck K, Kerr T, Li K, Montaner J, Wood E: Modeling 10-year crack cocaine use trends in a Canadian setting. Drug Alcohol Rev 2010, 29(3):271-277.

16. DeBeck K, Kerr T, Li K, Fischer B, Buxton J, Montaner J, Wood E: Emergence of crack cocaine smoking as a risk factor for HIV seroconversion among injection drug users in Vancouver, Canada. CMAJ 2009, 181(9):585-589.

17. SFU News Editors: Crack use biggest street drug problem in B.C. Vancouverite 2010 [http://www.vancouverite.com/2010/07/25/crack-usebiggest-street-drug-problem-in-b-c/]

18. Teichroeb R: Vancouver faces a rising crack problem. Seattle pi 2000 [http://www.seattlepi.com/honduras/page04.shtml].

19. Edlin BR, Irwin KL, Faruque S, McCoy CB, Word C, Serrano Y, Inciardi JA, Bowser BP, Schilling RF, Holmberg SD: Intersecting Epidemics-Crack Cocaine Use and HIV Infection among Inner-City Young Adults. N Engl J Med 1994, 331(21):1422-1427.

20. Buchanan D, Tooze JA, Shaw S, Kinzly M, Heimer R, Singer M: Demographic, HIV risk behavior, and health status characteristics of "crack" cocaine injectors compared to other injection drug users in three New England cities. Drug Alcohol Depend 2006, 81(3):221-229.

21. Booth RE, Kwiatkowski CF, Chitwood DD: Sex related HIV risk behaviors: differential risks among injection drug users, crack smokers, and injection drug users who smoke crack. Drug Alcohol Depend 2000, 58(3):219-226

22. Cross JC, Johnson BD, Davis WR, Liberty HJ: Supporting the habit: income generation activities of frequent crack users compared with frequent users of other hard drugs. Drug Alcohol Depend 2001, 64(2):191-201.

23. DeBeck K, Shannon K, Wood E, Li K, Montaner J, Kerr T: Income generating activities of people who inject drugs. Drug Alcohol Depend 2007, 91(1):50-56.

24. Shannon K, Rusch M, Morgan R, Oleson M, Kerr T, Tyndall MW: HIV and $\mathrm{HCV}$ prevalence and gender-specific risk profiles of crack cocaine smokers and dual users of injection drugs. Subst Use Misuse 2008, 43(34):521-534.

25. McCoy CB, Lai S, Metsch LR, Messiah SE, Zhao W: Injection drug use and crack cocaine smoking: independent and dual risk behaviors for HIV infection. Ann Epidemiol 2004, 14(8):535-542.

26. Kral AH, Bluthenthal RN, Booth RE, Watters JK: HIV seroprevalence among street-recruited injection drug and crack cocaine users in 16 US municipalities. Am J Public Health 1998, 88(1):108-113.

27. Cook JA, Burke-Miller JK, Cohen MH, Cook RL, Vlahov D, Wilson TE, Golub ET, Schwartz RM, Howard AA, Ponath C, Plankey MW, Levine AM, Grey DD: Crack cocaine, disease progression, and mortality in a multicenter cohort of HIV-1 positive women. AIDS 2008, 22(11):1355-1363.

28. Booth RE, Kwiatkowski CF, Weissman G: Health-related service utilization and HIV risk behaviors among HIV infected injection drug users and crack smokers. Drug Alcohol Depend 1999, 55(1-2):69-78.

29. Blackwell T: 'Safe crack' houses urged. National Post 2009 [http://www. nationalpost.com/Safe+crack+houses+urged/2121292/story.html].

30. Stueck W: BC health officer calls for crack-inhaling rooms. Globe and Mail 2009, $A: 1-5$.

31. Fischer B, Rudzinski K, Ivsins A, Gallupe O, Patra J, Krajden M: Social, health and drug use characteristics of primary crack users in three mid-sized communities in British Columbia, Canada. Drugs: education, prevention and policy 2010, 17(4):333-353. 
32. Guillemette D: Vancouver to open illegal smoking site for crack cocaine. The Thunderbird 2009 [http://thethunderbird.ca/2009/10/30/vancouver-toopen-illegal-smoking-site-for-crack-cocaine/].

33. Canadian National Specialty Society for Community Medicine: NSSCM Position Statement: Supervised Drug Consumption Sites and InSite program. 2009 [http://www.nsscm.ca/files/ POSITION_ON_SUPERVISED_CONSUMPTION_SITES.pdf].

34. Canadian Institutes of Health Research: Funding decisions. 2010 [http:// www.cihr-irsc.gc.ca/e/193.html].

35. Collins CL, Kerr T, Kuyper LM, Li K, Tyndall MW, Marsh DC, Montaner JS, Wood E: Potential uptake and correlates of willingness to use a supervised smoking facility for noninjection illicit drug use. J Urban Health 2005, 82(2):276-284.

36. Shannon K, Ishida T, Morgan R, Bear A, Oleson M, Kerr T, Tyndall MW: Potential community and public health impacts of medically supervised safer smoking facilities for crack cocaine users. Harm Reduct J 2006, 3:1.

37. Kerr T, Stoltz J, Tyndall M, Li K, Zhang R, Montaner J, Wood E: Impact of a medically supervised safer injection facility on community drug use patterns: a before and after study. BMJ 2006, 332(7535):220.

38. Wood E, Lloyd-Smith E, Li K, Strathdee SA, Small W, Tyndall MW,

Montaner JS, Kerr T: Frequent needle exchange use and HIV incidence in Vancouver, Canada. Am J Med 2007, 120(2):172-179.

39. Rhodes T: The 'risk environment': a framework for understanding and reducing drug-related harm. International J Drug Policy 2002, 13(2):85-94.

40. Rhodes T, Singer M, Bourgois P, Friedman SR, Strathdee SA: The social structural production of HIV risk among injecting drug users. Soc Sci Med 2005, 61(5):1026-44.

41. Rhodes T: Risk environments and drug harms: A social science for harm reduction approach. Int I Drug Policy 2009, 20(3):193-201.

42. Fairbairn N, Small W, Shannon K, Wood E, Kerr T: Seeking refuge from violence in street-based drug scenes: women's experiences in North America's first supervised injection facility. Soc Sci Med 2008, 67(5):817-823.

43. DeBeck K, Wood E, Zhang R, Tyndall M, Montaner J, Kerr T: Police and public health partnerships: evidence from the evaluation of Vancouver's supervised injection facility. Subst Abuse Treat Prev Policy 2008, 3:11.

44. DeBeck K: Drug-related street disorder: Evidence for public policy responses. Published PhD Dissertation University of British Columbia, Vancouver, Canada; 2010.

doi:10.1186/1747-597X-6-4

Cite this article as: DeBeck et al.: Public crack cocaine smoking and willingness to use a supervised inhalation facility: implications for street disorder. Substance Abuse Treatment, Prevention, and Policy 2011 6:4.

\section{Submit your next manuscript to BioMed Central and take full advantage of:}

- Convenient online submission

- Thorough peer review

- No space constraints or color figure charges

- Immediate publication on acceptance

- Inclusion in PubMed, CAS, Scopus and Google Scholar

- Research which is freely available for redistribution

Submit your manuscript at www.biomedcentral.com/submit
Biomed Central 